\title{
Crenças de autoeficácia de estudantes e professores de Física do Ensino Superior
}

\author{
Self-efficacy beliefs of Higher Education Physics students and teachers \\ Creencias de autoeficacia de estudiantes y profesores de Física de \\ Educacíon Superior
}

Gustavo Bopsin ${ }^{1}$; Charles Guidotti ${ }^{\mathbb{D}}$

\section{RESUMO}

Neste artigo apresentamos um estudo que buscou investigar as crenças de autoeficácia de estudantes e professores de um curso de Licenciatura em Física ao aprender e ensinar física. Este estudo contou com a participação de oito estudantes e seis professores do referido curso de graduação. Os sujeitos responderam a questionários sobre suas crenças de autoeficácia em realizar determinadas tarefas no contexto de disciplinas de Física Geral e Experimental. Os resultados mostram que a maioria desses estudantes e professores possuem crenças de autoeficácia que variam de medianas a altas.

Palavras-chave: Crenças de autoeficácia; Ensino de Física; Ensino Superior.

\begin{abstract}
In this article we present a study that sought to investigate the self-efficacy beliefs of students and teachers of a Physics Degree course when learning and teaching physics. This study had the participation of eight students and six teachers from the aforementioned undergraduate course. The subjects answered questionnaires about their self-efficacy beliefs in performing certain tasks in the context of General and Experimental Physics disciplines. The results show that most of these students and teachers have self-efficacy beliefs ranging from medium to high.
\end{abstract}

Keywords: Self-efficacy beliefs; Physics Teaching; Higher Education.

\section{RESUMEN}

En este artículo presentamos un estudio que buscó investigar las creencias de autoeficacia de estudiantes y docentes de una carrera de Licenciatura en Física al momento de aprender y enseñar física. Este estudio contó con la participación de ocho estudiantes y seis profesores de la carrera antes mencionada. Los sujetos respondieron cuestionarios sobre sus creencias de autoeficacia para realizar determinadas tareas en el contexto de las disciplinas de Física General y Experimental. Los resultados muestran que la mayoría de estos estudiantes $y$ profesores tienen creencias de autoeficacia que van de media a alta.

Palabras clave: Creencias de autoeficacia; Enseñanza de la Física; Educación Superior.

\footnotetext{
${ }^{1}$ Licenciado em Ciências Exatas (ênfase em Física) pela Universidade Federal do Rio Grande (FURG), Santo Antonio da Patrulha/RS - Brasil. E-mail: gustavobopsin@gmail.com

${ }^{2}$ Licenciado em Física, Mestre e Doutor em Educação em Ciências (2014) e Professor Universidade Federal do Rio Grande (FURG), Santo Antonio da Patrulha/RS - Brasil. E-mail: charles.guidotti@gmail.com
} 


\section{INTRODUÇÃO}

A motivação no contexto educacional, em diferentes níveis de ensino, tem sido objeto de estudo de diversos autores (RUFINI; BZUNECK; OLIVEIRA, 2012; MARCHIORE e ALENCAR, 2009; RUIZ, 2003; CARDOSO e BZUNECK, 2004; SANTOS et al., 2011; OLIVEIRA, 2017; PORTO e GONÇALVES, 2017). No contexto do Ensino de Física, Clement, Custódio e Alves Filho (2014) investigam a motivação de estudantes de Ensino Médio, enquanto Ricardo e Freire (2007) discutem as concepções de estudantes do Ensino Médio sobre a Física. Em relação ao Ensino Superior, Custódio, Pietrocola e Cruz (2013) apresentam experiências emocionais como motivação dos estudantes da graduação para se tornarem professores de Física.

Dentre as muitas teorias comportamentais que fornecem explicações para a motivação, neste trabalho assumimos a perspectiva da Teoria Social Cognitiva, através do conceito das crenças de autoeficácia, para estudar aspectos motivacionais de estudantes e professores vinculados a um curso de Licenciatura em Física de uma Universidade Federal.

Na literatura, observamos estudos sobre crenças de autoeficácia no Ensino Superior, em especial a formação de professores pedagogos (ALLIPRANDINI e SOUZA, 2016; CIRÍACO e PIROLA, 2018), educadores físicos (SILVA; IAOCHITE; AZZI, 2010) e docentes em um contexto geral (RIBEIRO et al., 2019). No cenário das publicações sobre crenças de autoeficácia de estudantes no Ensino de Física, alguns estudos envolvem metodologias ativas (ESPINOSA; ARAUJO; VEIT, 2019; SELAU et al., 2019), formação inicial de professores (NETO; LIMA; STRUCHINER, 2019) e evasão de licenciandos (PIGOSSO; RIBEIRO; HEIDEMANN, 2020).

Seguindo essa perspectiva, neste artigo, apresentamos um estudo desenvolvido com oito estudantes e seis professores de um curso de Licenciatura em Física. O objetivo da pesquisa foi identificar as crenças de autoeficácia desses estudantes e professores ao aprender e ensinar Física. Para isso, elaboramos dois questionários que foram respondidos pelos participantes e os dados foram analisados de forma qualitativa.

A seguir apresentamos interlocuções teóricas sobre a Teoria Social Cognitiva e as crenças de autoeficácia; estudos que fundamentaram a construção dos instrumentos de pesquisa; a produção e análise dos dados coletados; e as considerações finais.

\section{INTERLOCUÇÕES TEÓRICAS SOBRE A TEORIA SOCIAL COGNITIVA E AS CRENÇAS DE AUTOEFICÁCIA}

A gênese da Teoria Social Cognitiva por Albert Bandura se deu em meados da década de 60 com a publicação do trabalho intitulado Vicarious Process: a case of no-trial learning. Nesse trabalho, Bandura (1965) apresentou resultados de estudos sobre a aprendizagem observacional que contrariavam a teoria dominante na época. Em meio às teorias behavioristas do início do século XX, Neal Miller e John Dollard publicam o seu trabalho Social Learning and Imitation, em 1941, sobre a aprendizagem observacional. Segundo eles, um modelo fornece uma pista social, o observador executa uma resposta a este estímulo e este ato reforça a tendência do sujeito a se comportar de forma imitativa. Entretanto, os resultados de Bandura indicavam que a aprendizagem observacional não exigia tais respostas ou reforçamento, mas sim ocorriam através de funções cognitivas (BANDURA, 2005). 
Entre as concepções principais da Teoria Social Cognitiva, temos o determinismo recíproco e a ideia de agência humana. O determinismo recíproco se caracteriza pela relação triádica entre os fatores cognitivos (pessoais), fatores ambientais e fatores comportamentais (BANDURA, 1978). Segundo os behavioristas, os fatores ambientais eram mais influentes para o comportamento, enquanto os humanistas acreditavam serem os aspectos cognitivos aqueles que mais influenciaram 0 comportamento. Entretanto, para Bandura, há uma relação de reciprocidade entre estes três fatores, em que nenhum deles é superior ao outro e que todos se influenciam mutuamente.

Em relação à agência humana, segundo Bandura (2001, p.2) "ser agente significa fazer as coisas acontecerem de maneira intencional, por meio dos próprios atos", ou seja, o indivíduo influencia seu próprio comportamento de modo intencional. A agência humana possui quatro características: intencionalidade, antecipação, autorreatividade e autorreflexão. A intencionalidade é representada pelo objetivo do indivíduo ao realizar um curso de ação. Por exemplo, um professor universitário que deseja ministrar uma disciplina de Física Básica da forma mais acessível possível aos seus estudantes. Após estabelecer a intenção a ser cumprida, vem o planejamento e é isso que caracteriza a antecipação. Em nosso exemplo anterior, a antecipação se caracteriza pela realização do planejamento da disciplina. Mas para que o objetivo seja cumprido, não basta planejar, é necessário realizar as ações do planejamento e é na etapa da autorreatividade que isto ocorre. O professor precisa construir seus materiais que serão utilizados em aula, seguindo seu planejamento, e efetivamente lecioná-la. Por último, a autorreflexão diz respeito a uma autoavaliação sobre o próprio comportamento. O professor deve refletir se está fazendo o necessário para que seu objetivo se cumpra ou se precisa aperfeiçoar seu planejamento.

Vinculado ao conceito de autorreflexão, temos as crenças de autoeficácia. De acordo com Bandura (1977), as crenças de autoeficácia são percepções que os indivíduos possuem sobre suas próprias habilidades ao realizar determinada tarefa buscando determinado desempenho. Não estamos avaliando aqui as habilidades dos indivíduos, mas sim suas crenças em suas habilidades. Se um indivíduo possui crenças de autoeficácia abaixo de suas habilidades, ele rapidamente se desmotivará e não conseguirá aprimorar seu potencial. Já se um indivíduo possui crenças de autoeficácia acima de suas habilidades, ele não conseguirá realizar as tarefas e não obterá o desempenho desejado, acarretando em frustração. O desejável é que os indivíduos tenham níveis de autoeficácia consistentes com suas reais habilidades (ESPINOSA et al., 2019).

Sobre as causas das crenças de autoeficácia, existem pelo menos quatro fontes principais segundo a Teoria Social Cognitiva, são elas: experiências de êxito, experiências vicárias, persuasão verbal e estados fisiológicos e afetivos. Experiências de êxito, que é a fonte mais influente, corresponde às experiências positivas ou negativas que possuímos. Experiências vicárias são as experiências influenciáveis de outros indivíduos e ocorre quando nos comparamos com outro sujeito e o vemos como semelhante. Se o outro obtém sucesso ou fracassa, nos sentimos influenciados por tais resultados. Já a persuasão verbal são os conselhos, sugestões e falas de outras pessoas que nos influenciam de maneira direta, por exemplo, se alguém nos diz que conseguiremos realizar alguma tarefa. E por último, estados fisiológicos e afetivos são sintomas físicos que podemos apresentar como ansiedade ou estresse devido a alguma tarefa e que podem diminuir nossas crenças de autoeficácia em realizá-la (BANDURA, 1997). Na próxima seção, discorremos em torno de pesquisas abrangendo crenças de autoeficácia no contexto do Ensino Superior, em especial na formação inicial de professores, que serviram de base para o desenvolvimento deste estudo. 


\section{CRENÇAS DE AUTOEFICÁCIA NO ENSINO SUPERIOR: FORMAÇÃO INICIAL DE PROFESSORES}

No âmbito da formação inicial de professores, Alliprandini e Souza (2016) apresentam uma análise das crenças de autoeficácia de formandos do curso de Pedagogia enquanto Ciríaco e Pirola (2018) investigam atitudes e crenças de autoeficácia de estudantes de Pedagogia que tiveram contato com a pesquisa em Educação Matemática em seus TCC's. Ainda em relação aos cursos de Licenciatura, Silva, Iaochite e Azzi (2010) investigam as crenças de autoeficácia de 159 licenciandos de Educação Física. Como resultados, os autores concluíram que os estudantes se perceberam com um nível alto de autoeficácia.

No Ensino de Física, Espinosa, Araujo e Veit (2019) e Selau et al. (2019) estudam as crenças de autoeficácia de licenciandos em relação às metodologias ativas Team Based Learning e Episódios de Modelagem, respectivamente. Neto, Lima e Struchiner (2019) investigam as crenças de autoeficácia de estudantes de Licenciatura em Física no contexto do Programa Institucional de Bolsas de Iniciação à Docência (PIBID), enquanto Pigosso, Ribeiro e Heidemann (2020) apresentam um estudo sobre a evasão do curso de Licenciatura em Física a partir de egressos do referido curso. Rocha (2020) apresenta um estudo de caso sobre crenças de autoeficácia de ingressantes de um curso de Licenciatura em Física.

No contexto dos professores do Ensino Superior, Ribeiro et al. (2019) avaliam a percepção de autoeficácia de 188 docentes do Ensino Superior de instituições privadas utilizando a Escala de Autoeficácia de Professores do Ensino Superior. Os autores realizam uma análise quantitativa e verificam que os principais fatores responsáveis pela autoeficácia dos professores são a satisfação, a persuasão social e as experiências pregressas. Ainda neste estudo, foi verificado que os docentes tinham um alto valor de percepção de autoeficácia para realizar suas tarefas docentes. Em relação ao Ensino de Física, uma recente revisão de literatura (BOPSIN e GUIDOTTI, 2021) indica uma escassez de estudos envolvendo crenças de autoeficácia de docentes do Ensino Superior.

\section{PRODUÇÃO DAS INFORMAÇÕES}

As crenças de autoeficácia sempre se referem a tarefas específicas. Com o único intuito de não poluir visualmente o texto e evitar escrever repetidamente "crenças de autoeficácia de estudantes ao aprender Física" e "crenças de autoeficácia de professores ao ensinar Física", sempre que escrevermos crenças de autoeficácia no contexto dos estudantes/licenciandos ou dos professores, estaremos nos referindo às crenças de autoeficácia no contexto já especificado.

\subsection{Instrumentos de pesquisa}

A fim de compreender as crenças de autoeficácia de licenciandos e professores de um curso de Licenciatura em Física de uma Universidade Federal, foram desenvolvidos dois questionários.

O primeiro questionário, com foco em produzir informações acerca das crenças de autoeficácia dos professores de Física em formação inicial, foi adaptado a partir do estudo desenvolvido por Espinosa et al. (2019). O questionário original foi aplicado como pré e pós-teste, em que objetivou verificar a diferença entre as crenças de autoeficácia de estudantes masculinos e femininos. Os autores também buscaram verificar a eficácia de estratégias ativas de ensino, como o Peer Instruction (MAZUR, 1997), em reduzir essa diferença entre as crenças de autoeficácia de homens e mulheres ao estudar Física. 
Os autores concluíram que, no início do semestre letivo, as mulheres possuíam crenças de autoeficácia mais baixas quando comparadas aos dos homens, mas ao final do semestre, essa diferença desapareceu quando se utilizou estratégias ativas de ensino.

A contar do instrumento de pesquisa, utilizado por Espinosa et al. (2019), constituímos o primeiro questionário (Anexo 1) com 20 itens com o formato de uma escala de confiança com 10 níveis e mais duas questões descritivas que tinham a finalidade de abrir espaço para que os estudantes escrevessem algo que não havia sido abordado nas 20 questões anteriores. Estes itens ou alternativas foram separados em quatro categorias, a saber: compreensão de conceitos de Física; resolução de problemas, trabalho colaborativo; e atividades de laboratório. 0 quadro a seguir mostra as alternativas correspondentes a cada categoria.

Quadro 1 - Categoria das alternativas do questionário dos estudantes.

\begin{tabular}{|l|c|}
\hline \multicolumn{1}{|c|}{ Categorias } & Alternativas \\
\hline 1) Compreensão de conceitos de Física & $a, b, j, k, l$ \\
\hline 2) Resolução de problemas & $e, g, m, p, s$ \\
\hline 3) Trabalho colaborativo & $d, f, o, q, r$ \\
\hline 4) Atividades de laboratório & $c, h, i, n, t$ \\
\hline
\end{tabular}

Fonte: autores.

Registramos que com o intuito de limitar o estudo, selecionamos as áreas Física Básica e Física Experimental para investigação. Por Física Básica, estamos nos referindo às disciplinas de Física I, Física II, Física III e Física IV e por Física Experimental estamos nos referindo às disciplinas de Física Experimental I e Física Experimental II.

Já o questionário aplicado aos professores, disponível no Anexo 2, foi desenvolvido com base no questionário de Rocha e Ricardo (2014) e Espinosa et al. (2019). Rocha e Ricardo (2014) desenvolveram um questionário para professores do Ensino Médio sobre tópicos de Física Moderna e Contemporânea. Para o nosso uso, adaptamos as questões sobre Física Moderna e Contemporânea para Física Básica e Física Experimental. Além disso, utilizamos o mesmo formato das questões de Espinosa et al. (2019). A partir disso, o questionário utilizado nesta pesquisa contou com 10 itens a serem respondidos de acordo com uma escala de confiança com 10 níveis e, novamente, mais duas questões descritivas com a mesma finalidade das do questionário dos estudantes. Estes itens foram separados em cinco dimensões diferentes: conhecimento de Física; atividades de ensino; interação com os estudantes, conceitos físicos, e resolução de problemas.

Quadro 2 - Categoria das alternativas do questionário dos professores.

\begin{tabular}{|c|c|}
\hline Categorias & Alternativas \\
\hline 1) Conhecimento de Física & $a, d$ \\
\hline 2) Atividades de ensino & b, c \\
\hline
\end{tabular}




\begin{tabular}{|l|c|}
\hline 3) Interação com os estudantes & e, f \\
\hline 4) Conceitos físicos & $\mathrm{g}, \mathrm{h}$ \\
\hline 5) Resolução de problemas & $\mathrm{i}, \mathrm{j}$ \\
\hline
\end{tabular}

Fonte: autores

Para avaliar a consistência interna dos questionários elaborados, calculou-se o coeficiente alfa de Cronbach para verificar a fidedignidade e consideramos a validação de conteúdo prévia dos estudos.

Em relação à validação de conteúdo, esta se caracteriza pela avaliação do instrumento de pesquisa por especialistas que verificam se o instrumento está realmente medindo o que se espera que se meça. Os instrumentos de pesquisa desenvolvidos por Espinosa et al. (2019) e Rocha e Ricardo (2014) foram validados por validação de conteúdo e como os questionários elaborados foram fortemente baseados nesses estudos, consideramos que eles medem as crenças de autoeficácia dos estudantes e professores em aprender e ensinar física, respectivamente.

\subsection{Caracterização dos participantes}

Participaram da pesquisa oito estudantes do curso de Licenciatura em Física que corresponderam a $100 \%$ do corpo discente do curso em 2020/2 (a menos do primeiro autor deste trabalho). A idade média dos estudantes foi de 23,4 anos e todos eles cursaram pelo menos a disciplina de Física I. No quadro a seguir, sintetizamos todas as informações referentes ao corpo discente participante da pesquisa.

Quadro 3 - Informações dos estudantes

\begin{tabular}{|c|c|c|c|}
\hline Estudante & Idade & Semestre & Disciplinas cursadas [1] \\
\hline E1 & 22 & 40 & I e II \\
\hline E2 & 24 & 50 & I \\
\hline E3 & 23 & 60 & I e II \\
\hline E4 & 23 & $6^{0}$ & I, II, III, ExI e ExII \\
\hline E5 & 26 & $6^{0}$ & I, II, III, IV, ExI e ExII \\
\hline E6 & 23 & $8^{0}$ & I, II, III, IV, ExI e ExII \\
\hline E7 & 24 & $8^{0}$ & I, II, III, IV e ExI \\
\hline E8 & 22 & $6^{0}$ & \\
\hline
\end{tabular}

Fonte: dados da pesquisa.

Em relação ao grupo de professores, participaram da pesquisa seis professores do curso de Licenciatura em Física que corresponderam a $100 \%$ do corpo docente do campo da Física do curso em 2020/2. A idade média dos professores foi de 43,5 anos e todos os professores ministraram ao 
menos duas das seis disciplinas consideradas na pesquisa. O tempo de serviço médio dos professores entrevistados foi de 14,6 anos e incluiu tanto tempo de serviço na Educação Básica quanto na Educação Superior. No quadro a seguir, sintetizamos algumas das informações referentes ao corpo docente participante da pesquisa.

Quadro 4 - Informações dos professores

\begin{tabular}{|c|c|}
\hline Professor(a) & Disciplinas ministradas \\
\hline P1 & I e III \\
\hline P2 & I, II e III \\
\hline P3 & II, III, IV, ExI e ExII \\
\hline P4 & I, II, III e ExI \\
\hline P5 & I, II, EXI e ExII \\
\hline P6 & I, II, III, IV, ExI e ExII \\
\hline
\end{tabular}

Fonte: dados da pesquisa.

Escolhemos omitir a idade e tempo de serviço de cada professor para preservar suas identidades. Em relação aos discentes, temos casos de estudantes que ingressaram no mesmo ano, mas atribuíram semestres diferentes, possivelmente devido a trancamentos e reprovações em disciplinas do curso. Além disso, as idades dos estudantes são muito próximas, dificultando suas identificações. Já os professores é uma população menor e com idade e tempo de serviço mais diversificados, o que facilitaria a identificação dos mesmos pelos leitores que pertencem a comunidade acadêmica do curso e do campus.

\section{ANÁLISE DAS INFORMAÇõES}

\subsection{Estudantes}

A análise dos dados obtidos com os questionários aplicados aos estudantes foi realizada considerando as categorias desenvolvidas no Quadro 1. A seguir, apresentamos as notas atribuídas pelos estudantes nos 20 itens do questionário.

Quadro 5 - Notas atribuídas pelos estudantes.

\begin{tabular}{|c|c|c|c|c|c|c|c|c|}
\hline & E1 & E2 & E3 & E4 & E5 & E6 & E7 & E8 \\
\hline a) & 90 & 90 & 50 & 80 & 90 & 80 & 80 & 85 \\
\hline b) & 80 & 70 & 50 & 75 & 80 & 70 & 80 & 85 \\
\hline c) & $\begin{array}{c}\text { não se } \\
\text { aplica }\end{array}$ & 50 & $\begin{array}{c}\text { não se } \\
\text { aplica }\end{array}$ & $\begin{array}{c}\text { não se } \\
\text { aplica }\end{array}$ & 90 & 70 & 100 & 50 \\
\hline
\end{tabular}




\begin{tabular}{|c|c|c|c|c|c|c|c|c|}
\hline d) & 90 & 60 & 20 & 85 & 90 & 70 & 100 & 75 \\
\hline e) & 100 & 40 & 50 & 75 & 70 & 60 & 70 & 95 \\
\hline f) & 70 & 40 & 30 & 80 & 80 & 70 & 80 & 85 \\
\hline g) & 80 & 70 & 60 & 75 & 70 & 70 & 70 & 50 \\
\hline h) & $\begin{array}{c}\text { não se } \\
\text { aplica }\end{array}$ & 50 & $\begin{array}{c}\text { não se } \\
\text { aplica }\end{array}$ & $\begin{array}{c}\text { não se } \\
\text { aplica }\end{array}$ & 90 & 50 & 100 & 85 \\
\hline i) & $\begin{array}{l}\text { não se } \\
\text { aplica }\end{array}$ & 50 & $\begin{array}{c}\text { não se } \\
\text { aplica }\end{array}$ & $\begin{array}{c}\text { não se } \\
\text { aplica }\end{array}$ & 80 & 70 & 100 & 85 \\
\hline j) & 90 & 60 & 70 & 90 & 80 & 70 & 90 & 85 \\
\hline k) & 90 & 50 & 70 & 80 & 60 & 70 & 80 & 75 \\
\hline I) & 80 & 50 & 70 & 75 & 80 & 80 & 50 & 85 \\
\hline m) & 80 & 70 & 70 & 75 & 60 & 90 & 70 & 100 \\
\hline n) & $\begin{array}{c}\text { não se } \\
\text { aplica }\end{array}$ & 40 & $\begin{array}{c}\text { não se } \\
\text { aplica }\end{array}$ & $\begin{array}{c}\text { não se } \\
\text { aplica }\end{array}$ & 70 & 60 & 100 & 100 \\
\hline o) & 90 & 80 & 60 & 80 & 90 & 80 & 80 & 100 \\
\hline p) & 90 & 70 & 80 & 85 & 70 & 70 & 80 & 85 \\
\hline q) & 90 & 70 & 50 & 85 & 70 & 60 & 70 & 100 \\
\hline r) & 90 & 80 & 80 & 95 & 80 & 100 & 100 & 100 \\
\hline s) & 90 & 80 & 100 & 80 & 80 & 80 & 70 & 100 \\
\hline t) & $\begin{array}{c}\text { não se } \\
\text { aplica }\end{array}$ & 40 & $\begin{array}{c}\text { não se } \\
\text { aplica }\end{array}$ & $\begin{array}{c}\text { não se } \\
\text { aplica }\end{array}$ & 70 & 60 & 90 & 85 \\
\hline
\end{tabular}

Fonte: dados da pesquisa.

Em relação à primeira categoria, compreensão de conceitos de Física, observamos que apenas dois estudantes, E2 e E3, atribuíram notas menores que 60 em pelo menos dois itens. Podemos observar que estes dois estudantes foram os únicos que cursaram apenas uma disciplina de Física, a saber Física I. O estudante E2 relata em umas das questões descritivas do questionário, "na aula de física 1 , sentia muita dificuldade de relacionar a fórmula com o conceito físico", o que evidencia sua nota baixa no item (k) referente à interpretação do significado físico de uma equação. Além disso, uma das principais fontes das crenças de autoeficácia são as experiências de êxito (BANDURA, 1977) e é possível que por terem tido menos contato com Física, quando comparados com os outros participantes, tivessem maior insegurança e menos referências positivas em relação aos conceitos de Física, diminuindo suas crenças nesse aspecto. 
Observamos que estudantes mais experientes, E5 e E7, atribuíram notas menores que 70 em apenas um item cada, enquanto que os estudantes E6 e E8 não atribuíram nenhuma nota menor que 70. A partir disso, compreendemos que experiências de êxito podem ter contribuído para manter elevadas as crenças de autoeficácia desses estudantes em relação à conceitos de Física. Os estudantes E1 e E4, apesar da pouca experiência nas disciplinas, apresentaram notas altas. Estes dois casos podem ser de estudantes com motivações intrínsecas em relação a compreensão dos conhecimentos de física. Motivação intrínseca e extrínseca são conceitos chave da teoria da autodeterminação (DECI e RYAN, 1985) e conforme Clement, Custódio e Alves Filho (2014), "motivação intrínseca se caracteriza pelo interesse e satisfação na atividade em si". Já a motivação extrínseca pode ser dividida em diferentes estágios, indo da regulação externa (estágio mais próximo da desmotivação) até a regulação integrada (estágio mais próximo da motivação intrínseca). Para averiguar a motivação desses estudantes, seria necessário um estudo mais aprofundado com eles levando em consideração este novo referencial teórico.

Em relação à segunda categoria, resolução de problemas, os estudantes E2 e E3 apresentaram as menores notas no item (e) referente à resolução de questões conceituais sozinhos em sala de aula. Essas notas são compatíveis com as obtidas na primeira categoria, uma vez que para responder questões conceituais, é necessário conhecimentos dos conceitos. Entretanto, a mesma compatibilidade não é observada no item (g), referente a resolução de problemas qualitativos de Física, já que a nota mais baixa foi atribuída pelo estudante E8 que já cursou cinco das seis disciplinas consideradas.

Os itens $(m)$ e (s) refletem a necessidade do conhecimento de Matemática para a resolução de problemas de Física. De acordo com Pietrocola (2002), a Matemática é uma linguagem com a qual podemos estruturar nosso conhecimento físico. Dessa forma, saber Matemática é indispensável para a resolução de problemas em Física. Todos os estudantes, com exceção do E5, apresentaram notas iguais ou maiores que 70 nesses itens. Isso pode indicar um nível de médio para alto de crenças de autoeficácia em resolver problemas de Física utilizando Matemática.

Em relação à terceira categoria, trabalho colaborativo, seis estudantes, E1, E4, E5, E6, E7 e E8, apresentaram notas superiores a 70 em relação aos cinco itens, com exceção do estudante E6 que atribuiu 60 ao item (q), que se refere ao ato de encorajar seus colegas a participar de discussões em grupos. Já os estudantes E2 e E3 apresentaram notas mais baixas em relação aos seus colegas. Novamente seria possível supor que a pouca experiência em disciplinas de Física possa ter influenciado os estudantes E2 e E3 a acreditarem possuir pouca capacidade em trabalhos colaborativos. Além disso, Espinosa, Araujo e Veit (2019), no contexto de uma metodologia ativa de ensino (Team Based Learning), trazem que as experiências vicárias são muito importantes para o trabalho colaborativo.

Segundo Pajares e Olaz (2008), as experiências vicárias se tornam mais relevantes quando os indivíduos não possuem experiência na tarefa a ser realizada. A influência de terceiros nas crenças de autoeficácia do sujeito se torna ainda mais evidente quando ele vê semelhanças entre si e os outros indivíduos. Dessa forma, os estudantes E2 e E3 possivelmente não se identificam de forma muito significativa com seus colegas, resultando em experiências vicárias baixas. Este aspecto é reforçado pelo fato de que ambos os estudantes possuem um perfil de disciplinas cursadas diferente dos demais estudantes. 
O estudante E3 apresentou notas muito abaixo em relação aos seus colegas, principalmente nos itens (d) e (f) que se referem à comunicação com os colegas sobre Física e o trabalho colaborativo junto com os colegas para completar uma tarefa complexa, respectivamente. Bandura (1978) traz um conceito muito importante dentro de sua Teoria Social Cognitiva que é o determinismo recíproco. De acordo com este conceito, há uma relação triádica entre aspectos pessoais, ambientais e comportamentais dos indivíduos e estes aspectos estão entrelaçados, um influenciando o outro. No caso do estudante E3, é possível que aspectos pessoais, como timidez, possam estar interferindo em aspectos comportamentais como a comunicação e o trabalho colaborativo com seus colegas, fazendo o crer não ser capaz de realizar tais tarefas. Para um melhor entendimento sobre as notas atribuídas pelo estudante E3 nesse aspecto, seria necessária uma investigação mais profunda do caso, possivelmente uma entrevista e um questionário à parte.

Em relação à quarta e última categoria, atividades de laboratório, dos oito estudantes, três responderam que não haviam cursado nenhuma disciplina de Física Experimental, e por isso foi solicitado que não respondessem os cinco itens referentes a atividades de laboratório uma vez que eles não haviam, ainda, experienciado atividades experimentais. Apenas um estudante (E2) respondeu não ter cursado disciplinas de Física Experimental, entretanto respondeu aos cinco itens referentes a atividades de laboratório. Como foi solicitado que os estudantes marcassem apenas as disciplinas concluídas, isto nos leva a concluir que este estudante chegou a cursar a disciplina, entretanto não foi aprovado. Inclusive, as notas atribuídas pelo estudante E2 foram as menores notas dentre os 5 estudantes que responderam aos itens sobre atividades de laboratório.

Sobre os outros quatro estudantes, o estudante E7 apresentou quatro notas máximas e uma nota igual a 90 e dentre todas as categorias estudadas essa foi a categoria na qual esse estudante atribuiu as maiores notas. Isso nos fornece um indicativo de que esse discente crê, principalmente, ser muito capaz de trabalhar com atividades experimentais. Já o estudante E6 apresentou uma nota 50 ao item (h), referente a coleta de dados enquanto conduz experimentos de Física e o estudante E8 apresentou esta mesma nota no item (c), referente ao planejamento de experimentos de Física em sala de aula ou no laboratório. Ambos os estudantes E7 e E6 já cursaram todas as disciplinas estudadas, entretanto atribuíram notas diferentes. Os conceitos de motivação intrínseca (CLEMENT; CUSTÓDIO; ALVES FILHO, 2014) poderiam explicar essa diferença nas crenças de autoeficácia desses estudantes.

Um aspecto muito importante que foi levantado por um dos respondentes, o estudante E5, foi a interferência da pandemia de Covid-19 em suas crenças de autoeficácia. Conforme o estudante nos relata:

Utilizei para responder o questionário o [nome do estudante] pré-pandemia, onde estava com os conteúdos quentes na memória, no exato momento em que respondo o questionário não me sinto tão confiante, porém creio que voltando a normalidade de estudos retornaria a me sentir confiante diante de antigos e novos conteúdos estudados. (ESTUDANTE 5)

Esse trecho nos mostra que a pandemia influenciou as crenças de autoeficácia desse estudante e pode ter influenciado as crenças de autoeficácia dos outros estudantes, assim como as dos professores, conforme veremos adiante. Segundo Gusso et al. (2020), em um estudo sobre a influência da pandemia no Ensino Superior, há muitas variáveis que influenciam no processo de ensino-aprendizagem como a quantidade de computadores vs a quantidade de pessoas que necessitam dessas máquinas; repertório de professores e estudantes para manejo da plataforma de 
ensino; tempo disponível dos alunos para estudos; e condições dos professores para planejar e implementar as condições de ensino.

\subsection{Professores}

A seguir apresentamos as notas atribuídas pelos professores nos 10 itens do questionário.

Quadro 6 - Notas atribuídas pelos professores.

\begin{tabular}{|l|l|l|l|l|l|l|}
\hline & P1 & P2 & P3 & P4 & P5 & P6 \\
\hline a) & 80 & 80 & 60 & 80 & 100 & 80 \\
\hline b) & 95 & 70 & 0 & 70 & 60 & 50 \\
\hline c) & 90 & 80 & 0 & 80 & 80 & 70 \\
\hline d) & 80 & 90 & 60 & 80 & 90 & 75 \\
\hline e) & 75 & 80 & 0 & 70 & 80 & 75 \\
\hline f) & 90 & 90 & 70 & 90 & 90 & 60 \\
\hline g) & 90 & 90 & 50 & 70 & 80 & 75 \\
\hline h) & 90 & 90 & 30 & 70 & 80 & 80 \\
\hline i) & 95 & 90 & 50 & 70 & 80 & 80 \\
\hline j) & 95 & 90 & 50 & 90 & 90 & 80 \\
\hline
\end{tabular}

Fonte: dados da pesquisa.

O item (a) aborda as crenças dos professores ao ensinar tópicos de Física para seus estudantes. $\mathrm{O}$ professor P5 atribuiu nota máxima, enquanto os professores P1, P2, P4 e P6 atribuíram nota 80 neste item. Esses professores se sentem altamente capazes de ensinar tópicos de Física aos seus estudantes. Já o professor P3 atribuiu uma nota inferior, a saber, 60. Conforme veremos adiante na verificação das notas atribuídas pelos professores, o professor P3 apresenta baixas crenças de autoeficácia nas tarefas solicitadas.

Os itens (b) e (c) correspondem às crenças dos professores em desenvolver atividades inovadoras em sala de aula e criar atividades de ensino em sala de aula, respectivamente. Os professores P2, P4, P5 e P6 atribuíram uma nota ligeiramente maior no item (c) do que no item (b). Veja que não especificamos quais atividades de ensino de Física seriam essas, ou seja, eles se sentem menos capazes de desenvolver atividades inovadoras do que criar atividades no ensino de física. 0 professor P1 apresentou uma nota alta em ambos os itens e ele se sente mais capaz de criar atividades inovadoras do que desenvolver atividades no ensino de Física.

O caso do professor P3 é curioso, pois atribuiu notas nulas para ambas as atividades, indicando crer ser incapaz de implementar mudanças didáticas em sua prática. A crença da incapacidade de realizar atividades didáticas em sala de aula pode ser um reflexo da formação desse profissional. Se ele não teve, em sua formação, momentos nos quais foram necessários preparar planos de aula ou atividades inovadoras para serem aplicadas em sala de aula, é possível que não se sinta seguro para fazê-lo agora. Além disso, há o fator pessoal que também interfere nessa tomada de decisão. Conforme 
discutimos anteriormente, tanto aspectos ambientais quanto pessoais podem influenciar 0 comportamento humano através do mecanismo do determinismo recíproco. (BANDURA, 1978). Para aprofundarmos o porquê destas notas nulas nestes itens, seria necessária uma entrevista com este docente.

Já o item (d) se refere às crenças dos professores em relação a transposição dos conhecimentos aprendidos na sua formação para a sala de aula. Os professores P2 e P5 atribuíram nota 90, enquanto os professores P1 e P4 atribuíram nota 80, indicando uma crença de autoeficácia alta nessa tarefa. O professor P6 atribuiu nota 75 e novamente, o professor P3 atribuiu a menor das notas, 60. 0 estudo de Silva et al. (2011) encontra uma correlação entre a formação acadêmica dos professores e sua motivação em relação ao ensino. Em nosso caso, é possível que haja uma relação entre a motivação dos professores em transpor os conhecimentos aprendidos e a sua formação. Para aprofundar esse tópico do estudo, seria necessário verificar aspectos da formação desses profissionais e como eles se relacionam com sua própria motivação.

Os itens (e) e (f) refletem as crenças dos professores em relação à interação com seus estudantes. Com relação ao item (f), sobre responder às perguntas dos estudantes sobre Física em sala de aula, os professores P1, P2, P4 e P5 se sentem muito capazes tendo atribuído uma nota igual a 90. Já os professores P3 e P6 atribuíram notas menores, 70 e 60, respectivamente. Em relação ao item (e), sobre motivar os estudantes através do ensino-aprendizagem de tópicos de Física, vemos que todos atribuíram notas menores que no item (f). As notas dos professores P1, P2, P4, P5 e P6 oscilaram entre 70 e 80. Novamente, o professor P3 atribuiu nota zero nesse item, indicando crer ser incapaz de motivar seus estudantes em sala de aula. Conforme Goya, Bzuneck e Guimarães (2008) aponta em seu estudo, alunos motivados alimentam as crenças de autoeficácia de seus professores. Uma hipótese que pode indicar essa nota baixa é a de que, se for o caso, as aulas tradicionais desse professor podem estar desmotivando os estudantes e consequentemente o desmotivando.

Os itens ( $\mathrm{g}$ ) e (h) abordam as crenças dos professores em relação aos conceitos físicos trabalhados em aula. $\mathrm{O}$ item (g) trata da crença do professor em tornar claros os conceitos de Física aos seus estudantes, enquanto o item (h) trata da crença do professor em relacionar os conceitos físicos com aplicações cotidianas. Os professores P1, P2, P4 e P5 atribuíram às mesmas notas nos dois itens, a saber, 90, 90, 70 e 80, respectivamente. O professor P6 atribuiu 75 ao item (g) e 80 ao item (h). Já o professor P3 atribuiu notas diferentes e muito menores que seus colegas. Esse professor atribuiu notas 50 ao item (g) e 30 ao item (h).

Ainda em relação aos itens $(\mathrm{g})$ e ( $\mathrm{h})$, sobre as crenças de autoeficácia dos professores em tornar claro os conceitos físicos e relacioná-los com aplicações cotidianas, Chevallard (1991) nos trás a ideia de transposição didática, ou seja, as transformações sofridas pelos saberes oriundos dos cientistas até chegar na sala de aula. No contexto do Ensino Superior, muitas vezes, esses mesmos cientistas são professores, entretanto, os saberes tratados em sala de aula foram transpostos, através do uso de livros-texto ou notas de aula, para uma linguagem diferente daquela a qual foi formulada primeiramente.

Os itens (i) e (j) tratam das crenças dos professores em relação à resolução de problemas em Física. $\mathrm{O}$ item (i) aborda a crença de resolver problemas qualitativos em Física, enquanto o item (j) aborda a crença em ser capaz de realizar cálculos matemáticos para resolver problemas de Física. Os professores P1, P2 e P6 atribuíram, em ambos os itens, as notas 95, 90 e 80, respectivamente, indicando se sentirem altamente capazes de resolver problemas em Física. Os professores P4 e P5 
atribuíram nota 70 e 80 no item (i), respectivamente, e ambos atribuíram nota 90 no item (j). Novamente o professor P3 atribuiu notas menores que seus colegas, 50 em ambos os itens.

Em relação a estes dois itens, os professores de Física possuem uma sólida formação conceitual em Física e em Matemática que Ihes possibilita trabalhar com resolução de problemas de Física. Entretanto, vale ressaltar, como Bzuneck (2001) nos lembra, não estamos avaliando aqui as capacidades ou habilidades dos professores, mas sim suas crenças em suas capacidades e habilidades. O fato do professor P3 atribuir notas relativamente baixas aqui nos informa que ele possui crenças de autoeficácia baixas em relação a essas tarefas e não que ele possua baixas habilidades nesses campos.

\section{CONSIDERAÇÕES FINAIS}

Neste artigo apresentamos uma pesquisa realizada com estudantes e professores de um curso de Licenciatura em Física com o objetivo de verificar as crenças de autoeficácia desses indivíduos. As crenças de autoeficácia são um construto psicológico desenvolvido por Bandura (1977) e são definidas como as percepções que os indivíduos possuem sobre realizar determinada tarefa buscando determinado desempenho. Estudantes e professores responderam a questionários próprios sobre suas crenças de autoeficácia em relação a tarefas no contexto de disciplinas de Física Geral e Experimental.

Os resultados obtidos e as questões levantadas neste estudo nos indicam um pequeno reflexo da motivação e das crenças de autoeficácia de estudantes e professores do referido curso em aprender e ensinar Física. Em nossa pesquisa, um dos professores apresentou, em sua maioria, crenças de autoeficácia ao ensinar física mais baixas que seus colegas. O estudo foi realizado no contexto específico de disciplinas de Física Básica, entretanto o conceito das crenças de autoeficácia também se estende a disciplinas mais específicas do curso. Logo, é desejável que os professores ministrem as disciplinas em que se sentem mais capazes e confiantes e que estejam mais alinhadas com altas crenças de autoeficácia ao ensinar Física. Conforme Goya, Bzuneck e Guimarães (2008) nos mostram que, no contexto do Ensino Médio, há um ciclo que se retroalimenta entre a motivação de professores e de seus alunos. Deste modo, os professores ministrando as disciplinas em que se sentem mais confiantes, poderiam se sentir mais motivados, resultando em uma possível melhora na motivação de seus alunos.

Alguns aspectos que surgiram durante este estudo e que podem ser melhor investigados em pesquisas posteriores são investigar as motivações intrínsecas que podem ter influenciado as crenças de autoeficácia dos indivíduos participantes; verificar a influência da pandemia nas crenças de autoeficácia de estudantes e professores ao realizar tarefas específicas no contexto do Ensino de Física; e verificar a relação entre formação acadêmica dos professores e suas crenças de autoeficácia e motivação. Além disso, sugerimos que em estudos posteriores, se for possível, sejam realizadas entrevistas com os sujeitos a fim de aprofundar alguns aspectos deixados em aberto aqui.

Para trabalhos posteriores, sugerimos realizar além de uma pesquisa em relação a verificação das crenças de autoeficácia de estudantes e professores, realizar a verificação das capacidades desses indivíduos em relação às mesmas tarefas nas quais as crenças de autoeficácia foram medidas. Dessa forma, poder-se-ia comparar as crenças de autoeficácia com as capacidades e verificar se elas são superiores às capacidades, gerando frustração quando algum resultado esperado não é obtido; 
inferiores às capacidades, gerando insegurança no momento de realizar as tarefas; ou nos mesmos níveis das capacidades, que seria a situação ideal.

\section{NOTAS}

[1] Utilizamos a seguinte nomenclatura: I corresponde à Física I; II corresponde à Física II; III corresponde à Física III; IV corresponde à Física IV; ExI corresponde à Física Experimental I; e ExII corresponde à Física Experimental II.

\section{REFERÊNCIAS}

ALLIPRANDINI, P. M. Z.; SOUZA, D. A. A crença de autoeficácia de formandos de um curso de Pedagogia em relação ao exercício profissional. Educação em Análise. v. 1, n. 2, p. 215-235, jul/dez. 2016.

BANDURA, A. Vicarious processes: a case of no-trial learning. In: BERKOWITZ, L. (Ed.). Advances in experimental social psychology. New York: Academic Press, 1965. v.2, p.1-55.

BANDURA, A. Self-Efficacy: Toward a Unifying Theory of Behavioral Change. Psychological Review. v. 84 , n. 2, p. 191-215, 1977.

BANDURA, A. The Self System in Reciprocal Determinism. American Psychologist. v. 33, n. 4, p. 343-358, abr. 1978.

BANDURA, A. Self-Efficacy: The Exercise of Control. New York: Freeman, 1997.

BANDURA, A. Social Cognitive Theory: An Agentic Perspective. Annual Reviews Psychologist. v. 52 , p. 1-26, 2001.

BANDURA, A. The Evolution of Social Cognitive Theory. In: Smith K. G. e Hitt, M. A. (Eds.), Great Minds in Management. Oxford: Oxford University Press. 2005.

BOPSIN, G.; GUIDOTTI, C. Crenças de autoeficácia: uma revisão de literatura no contexto do ensino de física. Revista de Enseñanza de la Física. v. 33, n. 1, p. 7-19, jun. 2021.

BZUNECK, J. A. As Crenças de Auto-Eficácia e o seu Papel na Motivação do Aluno. In E. Boruchovitch \& J.A. Bzuneck (Org.) A Motivação do Aluno: Contribuições da Psicologia Contemporânea. Petrópolis: Editora Vozes; 116-133. 2001.

CARDOSO, L. R.; BZUNECK, J. A. Motivação no Ensino Superior: metas de realização e estratégias de aprendizagem. Psicologia Educacional e Escolar. v. 8, n. 2, p.145-155. 2004.

CHEVALLARD, Y. La transposición didáctica: del saber sabio, al saber enseñado. Buenos Aires. Editora Aique. 1991.

CIRÍACO, K. T.; PIROLA, N. A. "A Matemática, ela assusta um pouco": crença de autoeficácia e mudança de atitudes de estudantes de pedagogia a partir da pesquisa na formação inicial. Revista Eletrônica de Educação Matemática. v. 13, n. 1, p. 147-162. 2018.

CLEMENT, L.; CUSTÓRIO, J. F.; ALVES FILHO, J. P. A Qualidade da Motivação em Estudantes de Física do Ensino Médio. Revista Electrónica de Investigación en Educación en Ciencias. v. 9, n. 1, p. 84-95, jul. 2014. 
CUSTÓDIO, J. F.; PIETROCOLA, M.; CRUZ, F. F. S. Experiências emocionais de estudantes de graduação como motivação para se tornarem prof de física. Caderno Brasileiro de Ensino de Física. v. 30, n. 1, p. 25-57, abr. 2013.

DECI, E. L.; RYAN, R. M. Intrinsic motivation and self-determination in human behavior. New York. Plenum Press. 1985.

ESPINOSA, T.; ARAUJO, I. S.; VEIT, E. A. Crenças de autoeficácia em aprender física e trabalhar colaborativamente: um estudo de caso com o método Team Based Learning em uma disciplina de Física Básica. Revista Brasileira de Ensino de Ciência e Tecnologia, v. 12, n. 1, p. 69-94, janabr. 2019.

ESPINOSA, T.; MILLER, K.; ARAÚJO, I.; MAZUR, E. Reducing the gender gap in students' physics selfefficacy in a team- and project-based introductory physics class. Physical Review Physics Education Research. v. 15, n. 010132. 2019.

GOYA, A.; BZUNECK, J. A.; GUIMARÃES, S. E. R. Crenças de eficácia de professores e motivação de adolescentes para aprender Física. Revista Brasileira de Psicologia Escolar e Educacional, v. 12, n. 2, p. 51-57, jan-jul. 2008.

GUSSO, H. L., et al. Ensino Superior em tempos de pandemia: diretrizes à gestão universitária. Educação \& Sociedade. v. 41, e238957, Campinas, set. 2020.

HEIDEMANN, L. A.; ARAUJO, I. S.; VEIT, E.A. Atividades experimentais com enfoque no processo de modelagem científica: Uma alternativa para a ressignificação das aulas de laboratório em cursos de graduação em física. Revista Brasileira de Ensino Física, v. 38, n. 1, 2016.

MARCHIORE, L. W. O. A.; ALENCAR, E. M. L. S. Motivação para aprender em alunos do Ensino Médio. Educação Temática e Digital, Campinas. v. 10, n. Esp, p.105-123, out. 2009.

MAZUR, E. Peer Instruction A User's Manual. Ed. Prentice-Hall. Upper Saddle River. 1997.

NETO, R. S.; LIMA, M. B.; STRUCHINER, M. Crenças de Autoeficácia Docente no Ensino de Física: Uma Análise sobre o Percurso de Formação Docente. Ensino, Saúde e Ambiente, v. 12, n. 3, p. 86-103, dez. 2019.

OLIVEIRA, E. S. Moivação no Ensino Superior: Estratégias e Desafios. Contexto \& Educação. v. 32, n. 101, p. 212-232, jan/abr. 2017.

PAJARES, F.; OLAZ, F. Teoria social cognitiva e auto-eficácia: uma visão geral. In A. Bandura, R. G. Azzi e S. Polydoro (Org.) Teoria Social Cognitiva: Conceitos Básicos. Porto Alegre: Artmed; 97$114,2008$.

PIETROCOLA, M. A matemática como estruturante do conhecimento físico. Caderno Catarinense de Ensino de Física. v. 19, n. 1, p. 89-109, ago. 2002.

PIGOSSO, L. T.; RIBEIRO, B. S.; HEIDEMANN, L. A. A Evasão na Perspectiva de quem Persiste: um Estudo sobre os Fatores que Influenciam na Decisão de Evadir ou Persistir em Cursos de Licenciatura em Física Pautado pelos Relatos dos Formandos. Revista Brasileira de Pesquisa em Educação em Ciências, v. 20, p. 245-273, jan-dez. 2020.

PORTO, R. C.; GONÇALVES, M. P. Motivação e envolvimento acadêmico: um estudo com estudantes universitários. Psicologia Educacional e Escolar. v. 21, n. 3, p. 515-522, set/dez. 2017. 
RIBEIRO, J. R. C.; BICALHO, C. C. F.; ONOFRE, M. T. A. S.; NOC, F. Autoeficácia em Professores do Ensino Superior. Revista de Ensino, Educação e Ciências Humanas. v. 20, n. 3, p. 319-323. 2019.

RICARDO, E. C.; FREIRE, J. C. A. A concepção dos alunos sobre a física do ensino médio: um estudo exploratório. Revista Brasileira de Ensino de Física. v. 29, n. 2, p. 251-266, 2007.

RUFINI, S. E.; BZUNECK, J. A.; OLIVEIRA, K. L. A Qualidade da Motivação em Estudantes do Ensino Fundamental. Revista Paidéia. v. 22, n. 51, p. 53-62, jan/abr. 2012.

RUIZ, V. M. Motivação na universidade: uma revisão da literatura. Revista Estudos de Psicologia. v. 20, n. 2, Campinas, p. 15-24, mai/ago. 2003.

ROCHA, D. M. Crenças de autoeficácia e estratégias de aprendizagem: um estudo de caso dos ingressantes no curso de Licenciatura em Física. Pesquisa e Ensino em Ciências Exatas e da Natureza. v. 4, p. 01-16, jul. 2020.

ROCHA, D. M.; RICARDO, E. C. As crenças de autoeficácia de professores de Física: um instrumento para aferição das crenças de autoeficácia ligadas a Física Moderna e Contemporânea. Caderno Brasileiro de Ensino de Física, v. 31, n. 2, p. 333-364, ago. 2014.

SANTOS, A. A. A.; MOGNON, J. F.; LIMA, T. H.; CUNHA, N. B. A relação entre vida acadêmica e a motivação para aprender em universitários. Psicologia Educacional e Escolar. v. 15, n. 2, p. 283290, jul/dez. 2011.

SELAU, F. F.; ESPINOSA, T.; ARAUJO, I. S.; VEIT, E. A. Fontes de autoeficácia e atividades experimentais de física: um estudo exploratório. Revista Brasileira de Ensino de Física, v. 41, n. 2, 2019.

SILVA, A. J.; IAOCHITE, R. T.; AZZI, R. G. Crenças de autoeficácia de licenciandos em Educação Física. Motriz. Revista de Educação Física. v. 16, n. 4, p. 942-949, out/dez. 2010.

SILVA, F. R.; BARROS, M. A.; LABURÚ, C. E.; SANTOS, L. C. A. Crenças de eficácia, motivação e a formação de professores de física. Caderno Brasileiro de Ensino de Física, v. 28, n. 1, p. 214228, abr. 2011.

Submissão: 06/07/20211

Aceito: 17/01/2022 


\section{ANEXO 1}

\section{Questionário - estudantes}

Termo de consentimento livre e esclarecido

O(a) senhor(a) está sendo convidado a participar de uma pesquisa de graduação sobre crenças de autoeficácia no Ensino de Física. Os participantes da pesquisa serão os estudantes no curso de Licenciatura em Ciências Exatas - ênfase em Física.

$O(a)$ Senhor(a) não terá despesas e nem será remunerado pela participação na pesquisa. Todas as despesas decorrentes de sua participação na pesquisa não serão cobradas.

O risco da pesquisa é mínimo por envolver apenas a resposta ao questionário online, o qual foi elaborado com o intuito de que o tempo gasto para seu preenchimento seja mínimo, em torno de 5 a 10 minutos. Para garantir a confidencialidade e a privacidade dos indivíduos, a caracterização dos mesmos será feita por codificação de sua identidade. Todos os dados obtidos na pesquisa serão utilizados exclusivamente com finalidades científicas conforme previsto no consentimento do participante. Os resultados da pesquisa não serão divulgados a terceiros.

Não existe benefício ou vantagem direta em participar deste estudo. Os benefícios e vantagens em participar são indiretos, proporcionando retorno social através de melhorias no currículo do curso e da publicação dos resultados da pesquisa em periódicos científicos. Remotamente as pessoas que estarão acompanhando os procedimentos serão os pesquisadores: e Prof. Dr. , que são os responsáveis pela pesquisa.

O(a) senhor(a) poderá se retirar do estudo a qualquer momento, sem qualquer necessidade de justificativa. Solicitamos a sua autorização para o uso de seus dados para a produção de artigos técnicos e científicos. A sua privacidade será mantida através da não identificação do seu nome.

[ ] Aceito participar da pesquisa e declaro que li todos os termos acima descrito

Nome:

Idade:

Semestre:

[ ] $1^{\circ}$ semestre [ ] $2^{\circ}$ semestre [ ] $3^{\circ}$ semestre [ ] 40 semestre [ ] $5^{\circ}$ semestre

[ ] $6^{\circ}$ semestre [ ] $7^{0}$ semestre [ ] $8^{\circ}$ semestre

Quais disciplinas você já cursou? Marque apenas as disciplinas concluídas.

$\begin{array}{lllll}\text { [ ] Física I } & \text { [ ] Física II [ ] Física II } & \text { [ ] Física IV } \\ \text { [ ] Física Experimental I } & \text { [ ] Física Experimental II }\end{array}$

1) Para cada afirmação, avalie o seu grau de crença na sua habilidade de realizar as seguintes tarefas (referentes à Física Básica - disciplinas de Física I e/ou II e/ou III e/ou IV e/ou Experimental I e/ou Experimental II) registrando um número de 0 à 100 utilizando a escala indicada. Se você ainda não cursou nenhuma disciplina de Física Experimental, escreva apenas "Não se aplica", nos itens "c", "h", "i", "n" e "t".

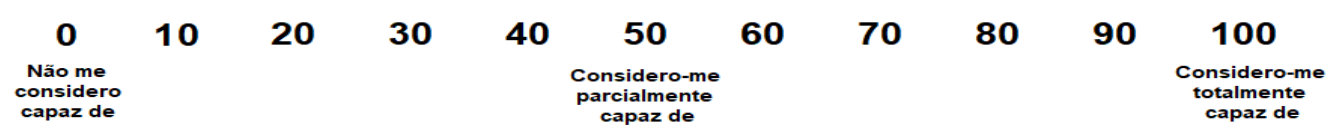

(a) entender conceitos físicos.

(b) relacionar diferentes conceitos físicos entre si.

(c) planejar experimentos de física em atividades manuais (em sala de aula ou no laboratório).

(d) comunicar física de uma maneira que meus colegas entendam.

(e) responder questões conceituais sozinho em sala de aula. 
(f) trabalhar junto com meus colegas para completar uma tarefa complexa.

(g) resolver problemas qualitativos de física.

(h) coletar dados enquanto conduz experimentos de física.

(i) escrever relatórios resumindo experimentos de física.

(j) relacionar conceitos físicos com aplicações cotidianas.

(k) interpretar o significado físico de uma equação.

(I) interpretar gráficos que explicam fenômenos físicos.

(m) realizar cálculos matemáticos enquanto resolve problemas de física.

(n) usar equipamentos durante atividades manuais.

(o) ser flexível quanto aos conflitos e desacordos em trabalhos em grupos.

(p) avaliar a plausibilidade de resultados físicos.

(q) em atividades em grupos, encorajar meus colegas a participar das discussões.

(r) em uma discussão, escutar a opinião dos meus colegas, mesmo quando eu acho que estou certo.

(s) aplicar equações físicas para resolver problemas de física.

(t) interpretar dados enquanto conduz experimentos de física.

2) Existe algum aspecto que não foi destacado nas questões anteriores que você gostaria de mencionar?

3) Neste espaço, você pode fazer comentários que esclareçam suas respostas ou comentar algo que julgue ser pertinente. 


\section{ANEXO 2}

\section{Questionário - professores}

O objetivo deste questionário é averiguar o nível das crenças de autoeficácia dos professores de Física do curso de Licenciatura em Ciências Exatas referente à tarefas específicas relacionadas com as disciplinas de Física Básica do referido curso. As informações solicitadas serão utilizadas no Trabalho de Conclusão do acadêmico Gustavo Barbosa Bopsin sob a orientação do Prof. Dr. Charles Guidotti.

Termo de consentimento livre e esclarecido

O(a) senhor(a) está sendo convidado(a) participar de uma pesquisa de graduação sobre crenças de autoeficácia no Ensino de Física. Os participantes da pesquisa serão os professores de Física do curso de Licenciatura em Ciências Exatas.

$O(a)$ senhor(a) não terá despesas e nem será remunerado pela participação na pesquisa. Todas as despesas decorrentes de sua participação na pesquisa não serão cobradas.

o risco da pesquisa é mínimo por envolver apenas as respostas ao questionário online, o qual foi elaborado com o intuito de que o tempo gasto para seu preenchimento seja mínimo, em torno de 5 à 10 minutos. Para garantir a confidencialidade e a privacidade dos indivíduos, a caracterização dos mesmos será feita por codificação de sua identidade. Todos os dados obtidos na pesquisa serão utilizados exclusivamente com finalidades científicas conforme previsto no consentimento do participante. Os resultados da pesquisa não serão divulgados a terceiros.

Não existe benefício ou vantagem direta em participar deste estudo. Os benefícios e vantagens em particular são indiretos, proporcionando retorno social através de melhorias no currículo do curso e da publicação dos resultados da pesquisa em periódicos científicos. Remotamente as pessoas que estarão acompanhando os procedimentos serão os pesquisadores: Prof. Dr. que serão os responsáveis pela pesquisa.

O(a) senhor(a) poderá se retirar do estudo a qualquer momento, sem qualquer necessidade de justificativa. Solicitamos a sua autorização para o uso de seus dados para a produção de artigos técnicos e científicos. A sua privacidade será mantida através da não identificação do seu nome.

[ ] Aceito participar da pesquisa e declaro que li todos os termos acima descrito

Nome:

Idade:

Tempo de serviço:

Quais disciplinas você já ministrou?

$\begin{array}{llll}\text { [ ] Física I } & \text { [ ] Física II } & \text { [ ] Física II } \\ \text { [ ] Física Experimental I [ ] Física IV }\end{array}$

1) Para cada afirmação, avalie o seu grau de crença na sua habilidade de realizar as seguintes tarefas (referentes à Física Básica - disciplinas de Física I e/ou II e/ou III e/ou IV e/ou Experimental I e/ou Experimental II) registrando um número de 0 à 100 utilizando a escala indicada.

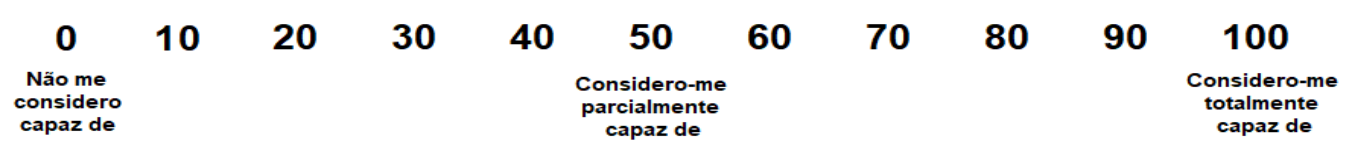

a) ensinar tópicos de física para meus estudantes.

b) desenvolver atividades inovadoras em sala de aula.

c) criar atividades de ensino de física em sala de aula. 
d) transpor para o Ensino Superior os tópicos de física aprendidos na minha formação (graduação e pós-graduação).

e) motivar meus estudantes através do ensino-aprendizagem de tópicos de física.

f) responder às perguntas dos estudantes sobre física em sala de aula.

g) tornar claros os conceitos da física aos meus estudantes.

h) relacionar conceitos físicos com aplicações cotidianas durante a aula.

i) resolver problemas qualitativos de física.

j) realizar cálculos matemáticos enquanto resolve problemas de física.

2) Existe algum aspecto que não foi destacado nas questões anteriores que você gostaria de mencionar?

3) Neste espaço, você pode fazer comentários que esclareçam suas respostas ou comentar algo que julgue ser pertinente. 